Trinity College

Trinity College Digital Repository

Faculty Scholarship

$5-2014$

Attitudes about Help-Seeking Mediate the Relation Between

Parent Attachment and Academic Adjustment in First-Year

College Students

Laura Holt

Trinity College, laura.holt@trincoll.edu

Follow this and additional works at: https://digitalrepository.trincoll.edu/facpub

Part of the Psychology Commons 


\section{PROJECT MUSE}

\section{Attitudes about Help-Seeking Mediate the Relation}

Between Parent Attachment and Academic Adjustmont in First-Year College Students

Journal of College Student Development, Volume 55, Number 4, May 2014, pp. 418-423 (Article)

Published by The Johns Hopkins University Press DOI: 10.1353/csd.2014.0039

$\Rightarrow$ For additional information about this article http://muse.jhu.edu/journals/csd/summary/v055/55.4.holt.html 
Lapchick, R. E. (1995). Academic standards for athletics in Black and White. Black Issues in Higher Education, 12, 48-50.

Lombardi, A. (2008). Student-athletes and learning disabilities. In A. Leslie-Toogood \& E. Gill (Eds.), Advising studentathletes: A comprehensive approach to success (pp. 31-35). Manhattan, KS: National Academic Advising Association.

Luchs, D., \& Dale, J. (2012, April 12). Pro sports can pay college athletes if schools won't. Retrieved from http://articles .businessinsider.com/2012-04-12/sports/31279815_1_collegescholarships-college-sports-food-stamps

Maniar, S., Chamberlain, R., \& Moore, N. (2005, November 7). Suicide is a real risk for student-athletes. Retrieved from http://fs.ncaa.org/Docs/NCAANewsArchive/2005/Editorial /suicide+risk+is+real+for+student-athletes+-+11-7-05+ncaa+ news.html

McCann, R. A., \& Austin, S. (1988). At-risk youth: Definitions, dimensions and relationships. Philadelphia, PA: Research for Better Schools. Retrieved from ERIC database. (UMI No. 307 359)

Meyer, S. K. (2005). NCAA academic reforms: Maintaining the balance between academics and athletics. Phi Kappa Phi Forum, 85, 15-18.

National Center for Education Statistics. (2007). Digest of education statistics, 2006. Washington, DC: U. S. Department of Education, Institute of Education Sciences.
National Collegiate Athletic Association. (2008, October 14). NCAA student-athletes graduating at highest rates ever. Retrieved from http://fs.ncaa.org/Docs/PressArchive/2008 /Academic\%2BReform/20081014_grad_success_rate_2_ release.html

Nordeen, L. (2006). The effectiveness of academic intervention programs within Division I intercollegiate athletics: An examination of race, gender, and sport type (Unpublished doctoral dissertation). University of Minnesota, Minneapolis.

Pinkerton, R. S., Hinz, L. D., \& Barrow, J. C. (1989). The college student-athlete: Psychological considerations and interventions. Journal of American College Health, 37, 218-226.

Sailes, G., \& Harrison, L. (2008). Social issues in sports. In A. Leslie-Toogood \& E. Gill (Eds.), Advising student-athletes: A comprehensive approach to success (pp. 13-21). Manhattan, KS: National Academic Advising Association.

Sellers, R. (2000). African American student athletes: Opportunity or exploitation. In D. Brooks \& R. Althouse (Eds.), Racism in college athletics (pp. 133-154). Morgantown, WV: Fitness Information Technology.

Sorensen, E. A., Sincoff, M. Z., \& Siebeneck, E. A. (2009). The need for an effective student-athlete pregnancy and parenting policy. Journal of Issues in Intercollegiate Athletics, 1, 25-45.

Wolverton, B. (2006, January). Graduation rates remain at record high. Chronicle of Higher Education, 52, A41-A43.

\title{
Attitudes about Help-Seeking Mediate the Relation Between Parent Attachment and Academic Adjustment in First-Year College Students
}

\author{
Laura J. Holt
}

\begin{abstract}
Although numerous studies have documented an association between parent attachment and college student adjustment, less is known about the mechanisms that underlie this relation. Accordingly, this short-term longitudinal study examined first-year college students' attitudes about academic help-seeking as one possible mechanism. As predicted, help-seeking attitudes mediated the relation between parent attachment and academic adjustment, even after controlling for gender and initial academic adjustment, with females holding more favorable attitudes about academic help-seeking. College personnel might explicitly encourage academic help-seeking in first-year students to maximize academic success
\end{abstract}

and mitigate the effects of insecure attachment and gender-specific socialization.

Although the transition to college is often a student's first major separation from parents, the quality of the student-parent relationship has been shown to have an enduring effect on student adjustment. Students who are securely attached to their parents (i.e., those who report high levels of trust, communication, and closeness) evidence better academic adjustment (Rice, FitzGerald, Whaley, \& Gibbs, 1995) and better psychological adjustment (Bradford \& Lyddon, 1993; Vivona, 2000) compared to insecurely attached students. Attachment 
quality is not only associated with numerous aspects of student functioning, but it also can influence the trajectory of student adjustment. Indeed, longitudinal investigations have shown that a secure attachment style in the first semester of college predicts better academic and emotional adjustment at later points in college (Bernier, Larose, Boivin, \& Soucy, 2004; Rice et al., 1995).

Given that attachment has been shown to be relatively stable throughout the transition to college (Larose \& Boivin, 1998), the identification of mechanisms that are more proximal to student adjustment is critical, as it could inform the development of universal programs for incoming students, as well as selective programs for students with parental relationships characterized by stress or detachment. Only recently have researchers begun to investigate mechanisms that account for the robust links between attachment and adjustment. For example, Larose and Bernier (2001) found that compared to their securely attached peers, insecurely attached students were lonelier, and this relation was mediated by worry about life events and reluctance to seek academic assistance from teachers. Lopez, Mitchell, and Gormley (2002) showed that problem-coping styles, namely selfsplitting and self-concealment, mediated the relation between an insecure attachment style and student maladjustment. These two studies converge in an important way, in that they suggest that insecure attachment may predispose students to avoid self-disclosure and help-seeking in the face of difficulty. Other constructs identified in this research, specifically self-splitting and worry, might be more appropriate to address in a counseling context; however, help-seeking could be readily addressed through supportive programming for first-year students.

Help-seeking attitudes and behaviors have been linked to parent attachment theo- retically and empirically. As described by Newman (2000), early supportive relationships promote the development of positive internal representations of oneself and others; in turn, these positive internal working models not only provide children with the necessary selfconfidence to seek help, but they also instill a sense that others can be relied on in the face of difficulty and that some challenges are best addressed collaboratively. In a college context, securely attached students might be more likely to seek help from professors, administrators, or even peers on account of constructive problem-solving experiences with a parent. Our understanding of help-seeking in college students is, however, largely limited to students' receptivity to college counseling or psychotherapy. Academic help-seeking, on the other hand, is an underexamined, yet critical issue to explore, given that the pronounced changes in academic expectations and classroom environments that accompany the college transition may discourage student outreach (Karabenick, 2003) and ultimately compromise student achievement. Accordingly, I examined first-year students' attitudes about academic-help seeking, defined as students' level of comfort with, and intentions to obtain assistance when they encountered challenging course content or experienced difficulties in a course. This construct was of interest because it is a more proximal and potentially modifiable influence on college academic adjustment (compared to parent attachment), and it also was thought to serve as a possible mediator of the attachment-adjustment relation. Based on previous research, it was hypothesized that higher levels of parent attachment would predict better academic adjustment, and help-seeking attitudes would mediate this effect. Also, based on a meta-analysis showing that college-age females had more favorable attitudes about seeking psychological help than males (Nam et al., 2010), it was expected that 
females would hold more positive attitudes about academic help-seeking.

\section{METHOD}

\section{Participants and Procedure}

Participants were 93 first-year students (64\% female) at a small, residential, liberal arts college in the Northeastern United States who responded to two Web-based surveys at the beginning (Time (1) and end of the first semester (Time (2). About half of all students $(284,48 \%)$ accessed the Time 1 survey and 204 (72\%) completed it. Chisquare tests confirmed that students who responded to the Time 1 survey did not differ from nonresponders with respect to gender, minority status, or financial aid status. Time 1 responders received an e-mail with a link to the Time 2 survey at the end of the semester; nonresponders received two additional e-mail invitations. About half $(93,46 \%)$ of the Time 1 respondents also completed the Time 2 survey; there were no significant differences on the study variables or the grade point averages of those who responded at Time 1 only and those who responded to both surveys. The mean age at Time 1 was 18.09 years $(S D=.53)$; $68 \%$ were White, $18 \%$ Asian / Asian American, 5\% Black / African American, 5\% Hispanic/Latino, and 3\% other. Students who completed one or both surveys were entered into lotteries for gift certificates to an online merchant. All research procedures were approved by the college's Institutional Review Board.

\section{Measures}

Parent Attachment. The 25-item Inventory of Parent and Peer Attachment (Armsden \& Greenberg, 1987) was used to assess first-year students' quality of communication, sense of security, and sense of alienation from their parents $(\alpha=.95$ in this study). In line with Bretherton's (1985) suggestion that the primary attachment figure influences one's internal working model more than other attachment figures, participants rated each statement in reference to the parent that influenced them most. Most participants $(77 \%)$ identified their mother as their primary attachment figure.

Attitudes About Academic Help-Seeking. Eight items from Karabenick's (2003) 13item help-seeking scale were used $(\alpha=.81)$ to assess participants' intentions to seek academic assistance if they were to encounter difficulty in one of their courses (e.g., "Getting help would be one of the first things I would do if I were having trouble in one of my courses").

Academic Adjustment. The 24-item Academic Adjustment scale from the 67-item Student Adaptation to College Questionnaire (Baker \& Siryk, 1989) was used to assess participants' academic functioning after the first semester of college $(\alpha=.86)$. This scale inquires about students' level of participation, motivation, and effectiveness in their courses and coursework preparations. To control for initial level of academic adjustment, 5 scale items that did not assume any college experience were administered at Time 1 .

\section{RESULTS}

In order to examine evidence for mediation, the test of the joint significance (TJS), or a test of the two effects comprising the mediator variable, was used (MacKinnon, Lockwood, Hoffman, West, \& Sheets, 2002). In the first regression model, the proposed intervening variable (attitudes about help-seeking) was regressed onto the independent variables (gender, parent attachment, T1 academic adjustment); then, in a second model, the dependent variable (T2 academic adjustment) was regressed onto the independent variables and intervening variable. Gender was examined 
both as a predictor of help-seeking attitudes and academic adjustment and as a potential moderator. Since the interaction terms with gender did not significantly change the $R^{2}$ values, only the main effects are reported. In Model 1, after controlling for gender and initial academic adjustment, higher levels of parent attachment predicted more favorable attitudes about academic help-seeking, and females held significantly more favorable attitudes about academic help-seeking. With respect to Model 2, which tested for mediation, the significant association between attitudes about help-seeking and academic adjustment suggests that, indeed, help-seeking attitudes served as an intervening variable. Figure 1 depicts the significant paths and illustrates the intervening variable effect.

\section{DISCUSSION}

In this study, attitudes about academic helpseeking, a potentially modifiable and proximal influence on academic adjustment, mediated the parent attachment-academic adjustment relation. These findings were consistent with research by Larose and Bernier (2001), who found that an insecure attachment style predicted more loneliness in college and that reluctance to seek help from teachers mediated this relation. The results extend this research specifying how parent relationships can affect academic functioning specifically. As suggested by Newman (2000), parent relationships shape students' ideas about the acceptability of engaging others when they encounter challenges, as well as students' beliefs about others' reliability. These findings indicate that even in college close relationships with parents are associated with less shame and embarrassment around obtaining academic assistance. Securely attached students likely perceive academic challenges as opportunities for engagement with others which, in turn, predict other effective academic behaviors including better organization, preparation, and classroom engagement.

Females endorsed more favorable attitudes about academic help-seeking. These findings extend those reported in a recent meta-

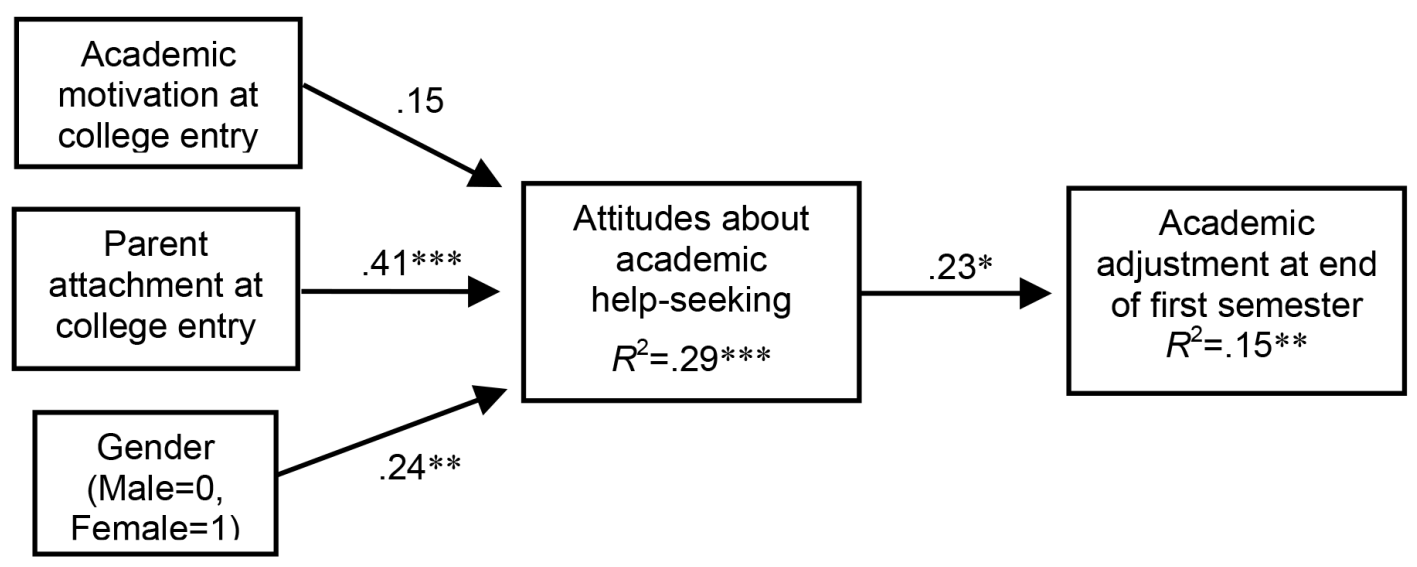

FIGURE 1. Mediational Model

Model predicting academic adjustment, with help-seeking as a mediator and parent attachment, gender, and academic motivation at college entry as independent variables. Values shown are standardized beta weights. $N=93$.

$* p \leq .05$, two-tailed. $\quad * * p \leq .01$, two-tailed. $\quad * * * p<.001$, two-tailed. 
analysis (Nam et al., 2010) and suggest that the gender difference observed in willingness to seek psychological help also is apparent with respect to academic help. Because gender differences in academic help-seeking have not been studied extensively at the college level, the reasons for this difference remain speculative. As described by Addis and Mahalik (2003), males' reluctance to seek help is motivated by a complex interaction of their socialization, the social construction of masculinity, and the meaning of giving and receiving help in a particular situation.

Several limitations of this study should be noted. This study relied on self-report measures and did not assess help-seeking behavior, so the extent to which attitudes about help-seeking were correlated with help-seeking behavior could not be determined. However, research suggests that behavioral intention ratings are valid predictors of future behavior (Karabenick \& Knapp, 1991). Although the response rates were similar to those reported in other studies of college students (Laguilles, Williams, \& Saunders, 2011), the sample constituted a relatively small percentage of the first-year class; thus, the findings might not generalize to all first-year students at this institution nor to students at dissimilar institutions (e.g., public institutions, community colleges).

To extend this research, it would be fruitful to examine attachment, help-seeking attitudes, and actual help-seeking behavior longitudinally. Prior research has shown that students whose attachment styles changed from secure to insecure evidenced a modest increase on some measures of distress (Lopez \& Gormley, 2002). Accordingly, an examination of attachment trajectories and their effects on academic adjustment could further elucidate how family dynamics are implicated in academic success. Moreover, since it is unlikely that college personnel can influence student attachment directly, other theoretically relevant and modifiable mediators of the attachmentadjustment relation should be explored.

\section{Implications}

To address the needs of first-year students with less secure attachments, it may be beneficial for faculty, staff, and other personnel to identify specific and appropriate help-seeking behaviors that students can enact upon encountering various academic challenges. Since previous research also has shown that students with insecure attachments harbor negative perceptions of their social support networks (Larose \& Boivin, 1998; Larose, Bernier, Soucy, \& Duchesne, 1999), faculty, staff, and other college personnel should explicitly emphasize their accessibility and their desire to help students navigate the college transition. Moreover, faculty, staff, and more experienced students (e.g., peer mentors, teaching assistants) who work with first-year male students could be advised to normalize the academic challenges inherent in the college transition and to share personal examples of difficulties experienced during this transition. College personnel should endeavor to change perceptions about the meaning of seeking academic help; initiating contact with professors and other academic support should be presented as a strategy of effective and successful students. More experienced students whom the first-year students regard as academically successful could be encouraged to model this behavior. This outreach and socialization may be especially critical in large university settings where students may feel more anonymous in their courses and in other settings where students may be more reticent to seek academic help, such as nonresidential colleges, institutions where there is a high percentage of first-generation college students, and/or less selective institutions. A multipronged approach such as the one suggested above likely would nor- 
malize academic challenges, recast them as attributable to the transition and not to student deficits, and engender more tolerance and encouragement for male student outreach and student outreach in general.

\section{REFERENCES}

Addis, M. E., \& Mahalik, J. R. (2003). Men, masculinity, and the contexts of help seeking. American Psychologist, 58, 5-14. doi:10.1037/0003-066X.58.1.5

Armsden, G. C., \& Greenberg, M. T. (1987). The inventory of parent and peer attachment: Individual differences and their relationship to psychological well-being in adolescence. Journal of Youth and Adolescence, 16, 427-454. doi:10.1007 /BF02202939

Bernier, A., Larose, S., Boivin, M., \& Soucy, N. (2004). Attachment state of mind: Implications for adjustment to college. Journal of Adolescent Research, 19, 783-806. doi:10.1177/0743558403260096

Baker, R. W., \& Siryk, B. (1989). Manual of the SACQ. Los Angeles, CA: Western Psychological Services.

Bradford, E., \& Lyddon, W. J. (1993). Current parental attachment: Its relation to perceived psychological distress and relationship satisfaction in college students. Journal of College Student Development, 34, 256-260.

Bretherton, I. (1985). Attachment theory: Retrospect and prospect. Monographs of the Society for Research in Child Development, 50(1-2), 3-35. doi:10.2307/3333824

Karabenick, S. A. (2003). Seeking help in large college classes: A person-centered approach. Contemporary Educational Psychology, 28, 37-58. doi:10.1016/S0361-476X(02)00012-7

Karabenick, S. A., \& Knapp, J. R. (1991). Relationship of academic help seeking to the use of learning strategies and other instrumental achievement behavior in college students. Journal of Educational Psychology, 83, 221-230. doi:10.1037/0022-0663.83.2.221

Laguilles, J. S., Williams, E. A., \& Saunders, D. B. (2011). Can lottery incentives boost Web survey response rates? Findings from four experiments. Research in Higher Education, 52, 537-553.

Larose, S., \& Bernier, A. (2001). Social support processes: Mediators of attachment state of mind and adjustment in late adolescence. Attachment \& Human Development, 3, 96-120. doi:10.1080/14616730010024762

Larose, S., Bernier, A., Soucy, N., \& Duchesne, S. (1999). Attachment style dimensions, network orientation and the process of seeking help from college teachers. Journal of Social and Personal Relationships, 16, 225-247. doi:10.1177/0265407599162006
Correspondence concerning this article should be addressed to Laura J. Holt, Department of Psychology, Trinity College, 300 Summit Street, Hartford, CT 06106; Laura.Holt@trincoll.edu

Larose, S., \& Boivin, M. (1998). Attachment to parents, social support expectations, and socioemotional adjustment during the high school-college transition. Journal of Research on Adolescence, 8, 1-27. doi:10.1207/s15327795jra0801_1

Lopez, F. G., \& Gormley, B. (2002). Stability and change in adult attachment style over the first-year college transition: Relations to self-confidence, coping, and distress patterns. Journal of Counseling Psychology, 49, 355-364. doi:10.1037/0022-0167.49.3.355

Lopez, F. G., Mitchell, P., \& Gormley, B. (2002). Adult attachment orientations and college student distress: Test of a mediational model. Journal of Counseling Psychology, 49, 460-467. doi:10.1037/0022-0167.49.4.460

MacKinnon, D. P., Lockwood, C. M., Hoffman, J. M., West, S. G., \& Sheets, V. (2002). A comparison of methods to test mediation and other intervening variable effects. Psychological Methods, 7, 83-104. doi:10.1037/1082-989X.7.1.83

Nam, S. K., Chu, H. J., Lee, M. K., Lee, J. H., Kim, N., \& Lee, S. M. (2010). A meta-analysis of gender differences in attitudes toward seeking professional psychological help. Journal of American College Health, 59, 110-116. doi:10.1080/07448481.2010.483714

Newman, R. S. (2000). Social influences on the development of children's adaptive help seeking: The role of parents, teachers, and peers. Developmental Review, 20, 350-404. doi:10.1006/drev.1999.0502

Rice, K. G., FitzGerald, D. P., Whaley, T. J., \& Gibbs, C. L. (1995). Cross-sectional and longitudinal examination of attachment, separation-individuation, and college student adjustment. Journal of Counseling \& Development, 73, 463-474.

Vivona, J. M. (2000). Parental attachment styles of late adolescents: Qualities of attachment relationships and consequences for adjustment. Journal of Counseling Psychology, 47, 316-329. doi:10.1037/0022-0167.47.3.316 